\title{
New Insights of Human Parvovirus B19 in Modulating Erythroid Progenitor Cells Differentiation
}

\author{
Shuwen Feng, Dongxin Zeng, Junwen Zheng*, Dongchi Zhao* \\ Pediatrics Department, Children Digital and Health Data Research Center, Zhongnan Hospital of \\ Wuhan University \\ Authors: Shuwen Feng fengshuwen@whu.edu.cn \\ Dongxin Zeng zengdongxin@163.com \\ *Correspondence Authors: Junwen Zheng* zhengjunwen@ whu.edu.cn \\ Dongchi Zhao*zhao_wh2004@hotmail.com;
}

\begin{abstract}
Background

Human parvovirus B19, a human pathogen of the erythroparvovirus genus, is responsible for a variety of diseases. Despite less symptoms caused by B19 infection in healthy individuals, this pathogen can not be neglected in specific groups who exhibit severe anemia.

\section{Main body of abstract}

Transient aplastic crisis and pure red cell aplasia are two kinds of anemic hemogram respectively in acute phase and chronic B19 infection, especially occur in individuals with a shortened red cell survival or immunocompromised patients. In addition, B19 infected pregnant women may suffer risks of hydrops fetalis secondary to severe anemia and fetal loss. B19 possesses high affinity to bone marrow and fetal liver due to its extremely restricted cytotoxicity to erythroid progenitor cells mediated by viral proteins. The nonstructural protein NS1 is considered to be the major pathogenic factor, which takes parts in differentiational inhibition and apoptosis of erythroid progenitor cells through inducing viral DNA damage responses and cell cycle arrest. The time phase property of NS1 activity during DNA replication and conformity to transient change of hemogram are suggestive of its role in regulating differentiation of hematopoietic cells, which is not completely understood.
\end{abstract}

\section{Conclusion}

In this review, we set up a hypothetic bridge between B19 NS1 and Notch signaling pathway or transcriptional factors GATA which are essential in hematopoiesis, to provide a new insight of the potential mechanism of B19-induced differentiational inhibition of erythroid progenitor cells.

Key Words: human parvovirus B19; nonstructural protein NS1; erythroid progenitor cells; differentiation; GATA; anemia

\section{Running title: B19 modulates EPCs differentiation}




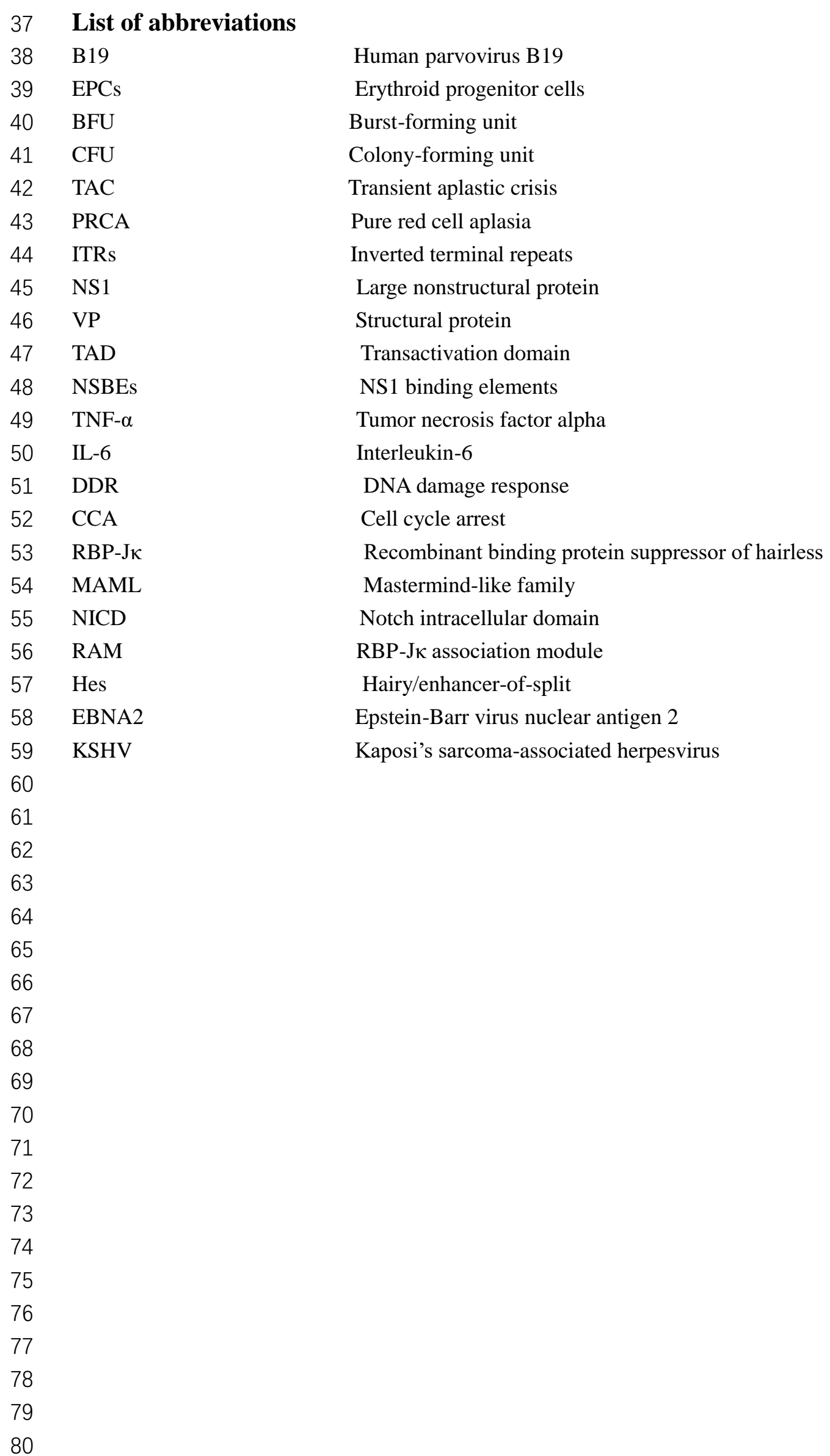




\section{Background}

Human parvovirus B19 (B19), a small non-enveloped, single-stranded DNA virus belonging to the genus erythroparvovirus of the Parvoviridae family[1], known to be the causative agent of the fifth disease (erythema infectiosum), is also a leading cause of autoimmune disease in human beings[2, 3]. B19 infection is common worldwide, showing age dependent and regional epidemiological differences with seasonal and annual cycles. B19 outbreaks feature with a peaking in winter or spring and a three to six-years cycle[1,4]. Evidences were found that the seroprevalence of B19 IgG varies widely from approximately $2 \%$ to $21 \%$ in children from 1 to 5 years of age, from $30 \%$ to $40 \%$ in adolescents, from $40 \%$ to $60 \%$ in adults, and more than $85 \%$ in elderly populations[5]. Despite of the increasing positive incidence of B19 IgG with age groups, acquisition is often during childhood via respiratory route and continues at low rates throughout adulthood[6, 7]. Although many individuals with B19 infection are asymptomatic or exhibit mild, nonspecific, cold-like symptoms, children aged 4-11 years usually present to have 'slapped cheek' facial rash, which is self-limited and generally needs no treatment[8]. However, clinical conditions associated with the B19 infection could be severe in those who has a shortened red cell survival, or in immunocompromised patients and pregnant women[5].

Not only B19 infection could cause erythema infectiosum or transient aplastic crisis in acute infectious period, but the persistent existence of B19 in bone marrow could lead to pure red cell aplasia in an immunocompromised host[9]. Life would be threatened in patients with shortened red cell survival due to their lack of timely supplements in B19-induced severe anemia[10]. Furthermore, pregnant women with B19 infection have higher risk of miscarriage or fetal complications[11]. The rate of vertical transmission during maternal parvovirus B19 infection is estimated at $33 \%$, with fetal complications occurring in $3 \%$ of infected women[12]. B19V poses a potential hazard to the fetus as crossing the placental barrier and infecting erythroid progenitor cells (EPCs) in bone marrow and fetal liver, it blocks fetal erythropoiesis leading to profound anemia, fetal hydrops and/or fetal death[13]. Once the fetus/newborns develop hydrops, treatments like intrauterine red blood cell transfusion or intravenous immunoglobin and digitalis may fail to rescue, with a survival rate of only $60-70 \%$ overall[ $[14,15]$.

B19 is a potent inhibitor of erythropoiesis, due to its highly restricted cytotoxicity to EPCs at the burst-forming unit (BFU)- and colony-forming unit (CFU)-erythroid stages[16, 17]. Severe anemia could appear in immunodeficiency patients or patients with shortened red cell survival under B19 infected conditions, fetus/newborns of B19 infected mothers as well. B19 is an important antigen for Eugenics[13]. However, pathogenesis of B19 is not completely clear on account of its difficulties in vitro culture, effective vaccines or antivirus drugs of B19 are of urgent shortage. 


\section{Pathogenesis of anemia in B19 infection}

Even though B19 infection is self-limited in healthy individuals, it is often associated with transient aplastic crisis (TAC) in children with sickle cell disease[18]. In patients with short life span of red blood cells, such as sickle cell anemia, hereditary spherocytosis, thalassaemia, or chronic hemolytic disease, severe anemia exacerbated by B19 infection could be fatal due to the acute hemolysis and temporary arrest of erythropoiesis occurring on the basis of chronic hemolytic anemia and increased destruction of red blood cells if transfusions are not available or not administered urgently. Even more seriously, chronic B19 infection could induce pure red cell aplasia (PRCA), which is exhibited in immunocompromised patients or transplant recipients on account of impaired ability of viral elimination [19]. And PRCA in the intrauterine B19-infected fetus may show ultrasonographic signs of general edema, such as subcutaneous edema, pleural effusion, pericardial effusion, ascites and placental edema. The main mechanism responsible for the non-immune hydrops fetalis is probably cardiogenic heart failure secondary to severe anemia[20].

The B19 virus can be transmitted mainly by respiratory tracts, also via blood or pooled-blood products, from a pregnant mother to her fetus, and possibly even from tattooing[1]. After overcoming the barrier of airway epithelium, vascular or placenta, B19 arrives into human body and initially interacts with $\mathrm{P}$ antigen (globoside), the primary low-affinity attachment sugar molecule abundantly expressed on the surface of erythroid progenitor cells, acting as an essential cellular receptor for B19[21]. However, P antigen is necessary for binding but not sufficient for parvovirus B19 entry into cells[22, 23]. Unlike mature human red blood cells, primary human erythroid progenitor cells, the major target cells of B19, not only express high levels of P antigen, but specifically express $\alpha 5 \beta 1$ integrins which permit $\beta 1$ integrin-mediated entry of parvovirus B19[24]. Moreover, Ku80 was identified in vitro nonerythroid cells to functions as a coreceptor for B19 infection together with P antigen and $\alpha 5 \beta 1$ integrins, which takes part in B19 binding and subsequent entry. Although originally known as a nuclear protein, Ku80 was found to have a high expression on the surface of erythroid progenitor cells expressing glycophorin A as well as on the surface of immune cells such as $\mathrm{CD} 20^{+}, \mathrm{CD}^{+}$, or $\mathrm{CD} 14^{+}$cells in bone marrow, which may explain the pathologic immunity in autoimmune diseases related to B19 infection[25]. Thus, B19 virion accomplishes its internalization inside EPCs through interaction with $\mathrm{P}$ antigen in the aid of $\alpha 5 \beta 1$ integrins and $\mathrm{Ku} 80$, and initiates its replication after entering the nucleus. Differential inhibition processes and apoptotic signals activated by massive replication of B19 eventually lead to cytolysis of EPCs and release of virions into the blood, which is consist with the transient high-titer viremia in the acute phase. Destruction of large amount of EPCs significantly influences the erythropoiesis and life span of red blood cells, which brings about acute hemolysis (Figure 1).

\section{Nonstructural protein NS1 is the major pathogenic factor in B19 infection B19 structure}

The B19 virion has a linear ssDNA genome of 5 to $6 \mathrm{~kb}$, and a nonenveloped, icosahedral 
protein shell of $\sim 280 \AA$ in diameter, known to be the smallest DNA virus so far[26, 27]. The 5,596 nucleotides(nt) long genome is made up of an internal coding sequence flanked on both sides by identical inverted terminal repeats (ITRs)[1]. These palindromes can acquire a hairpin configuration and serve as primers for complementary strand synthesis, while the central region genome encodes the 5 kinds of proteins of B19 virion[28]. The two structural proteins, VP1 and VP2, account for $4 \%$ and $96 \%$ capsid proteins to form the icosahedral protein shell, respectively[3]. The region of them shows a greater sequence variation in contrast to the large nonstructural protein(NS1) region that is highly conserved, which implies their function in host antivirus responses[28]. Expressions of the other two small nonstructural proteins of $11 \mathrm{kDa}$ and $7.5 \mathrm{kDa}$ were also documented[29, 30], the former one was suggested as a potent inducer of apoptosis via enhancing viral DNA replication and virion release [31, 32], while the function of $7.5 \mathrm{kDa}$ protein is inconclusive.

\section{Roles of nonstructural protein 1 in B19 infection}

The large nonstructural protein NS1, located predominantly to the nucleus, is the major pathogenic factor in B19 infection[33]. NS1 gene (616-2631bp) encodes its protein of 672 amino acids with a molecular mass of $\sim 78 \mathrm{kDa}$, which is of critical importance in both early virus DNA replication and transcription in B19 infected human erythroid progenitor cells[1]. NS1 has a N-terminal DNA-binding/nickase domain, a central domain displaying sequence motifs for helicase/ATPase, and a putative transactivation domain (TAD) at the C-terminus[34]. Researches implied that, with the help of the transcription factors Sp1/Sp3, NS1 N-terminal nuclease domain specifically binds to the origin of replication in the virus DNA, including the NS1 binding elements(NSBEs) and the overlapping P6 promoter DNA sequence, and the interaction between NS1 and virus DNA mediates the cleavage of DNA at the ITRs by melting the hairpinned ITRs to create a new 3'-OH and permit the following DNA synthesis[35-37]. Regulation of gene transcription of B19 NS1 is not confined to its own viral promoter, p6, it has also been identified in the transactivation of several host promoters, like tumor necrosis factor alpha (TNF- $\alpha$ ), interleukin-6 (IL-6), and p21, which may explain the pathogenesis of B19-associated inflammation and apoptosis[38-40].

Studies on mechanism of B19-induced differentiational inhibition and apoptosis have made progress in recent years[17, 31, 41, 42]. B19 infection could induce a broad range of DNA damage responses (DDR) in ex vivo-expanded human erythroid progenitor cells, by triggering phosphorylation of all the upstream kinases of each of three repair pathways: ATM, ATR, and DNA-PKcs[43], which is of critical importance for virus replication. And the infected cells were reported to have a cell cycle arrest (CCA) at both late S-phase and G2-phase, a point of the cell cycle at which cells contain 4N DNA[44-46]. Recent advantages revealed that, NS1 transactivated cellular gene expression through the TAD2 domain, activating the ATR-CHK1-CDC25C-CDK1 pathway in the B19-induced G2 arrest[17], which is independent of p53 activation and DDR triggered by increased viral replication[45]. Interaction between NS1 and E2F family of 
transcription factors enhanced the nuclear import of these repressive E2Fs and induced stable G2 arrest[47]. While the putative metal coordination motif in the endonuclease domain of B19 NS1 is critical for NS1-induced S phase arrest and DNA damage[45]. B19 NS1 has also been reported to induce CCA at G1-phase in NS1-expressing UT7/Epo-S1 cells[48]. Replication of B19 virus promotes its NS1 covalently binding with host cellar DNA, causing DDR mediated by helicase or nickase in NS1 central region. Subsequently occurs the activating of the DNA nick repair pathway initiated by poly (ADPribose) polymerase and the DNA repair pathways initiated by ATM/ATR[49]. And the DNA repair processes activated by extensive DDR accompanied with a significant decrease in the ATP levels of the cell, act as the direct reason leading to apoptosis. Besides, NS1-induced DDR may play an indirect role in facilitating viral DNA replication by arresting cell cycle at $\mathrm{G} 2$ or S phase, during which host DNA replication factors are available[50]. Presumably, NS1 could also interfere with the expression of unidentified host transcriptional factors, resultantly perturbs cell cycle progression and inhibit the differentiation of EPCs. While S-phase arrest enriches S-phase factors that favor viral DNA replication as a compromised outcome of B19 genome replication, G2 arrest halts erythropoiesis of EPCs and eventually leads to apoptosis, in which $11 \mathrm{kDa}$ protein may play a more efficient part $[1,31,46]$.

In addition, the roles of NS1 in modulation of inflammatory signaling by activation of STAT3/PIAS3 and NLRP3, in inhibition of $\mathrm{Na}+\mathrm{H}+$ exchanger activity, and in exacerbation of liver injury were also been documented [51-54], which may partly explain the pathogenesis of multiple B19-associated diseases (Figure 2).

As the abundant expression of B19 NS1 predominantly located in the nucleus of EPCs[47], the protein only takes on its activity during the replication of virus DNA while not participates in the processes of assembling and release, and loses its function as the elimination of B19 virions, which is in accordance with the transient erythropoietic arrest in aplastic crisis. The time phase property of NS1 activity and conformity to transient change of hemogram implied that NS1 activity is closely related to differentiation and apoptosis of hematopoietic cells. Despite of the enormous progress made in understanding the roles of B19 NS1 induced apoptosis, further studies are needed to explore the regulatory mechanism in NS1 induced inhibition of EPCs differentiation, which is essential for therapeutic treatments of B19 related anemia. Besides B19, other virus likes Epstein-Barr virus, could also inhibit erythroid lineage cells differentiation by interfering certain signaling pathways involving in hematopoietic dysfunction. Among these pathways, B19 replication and transcription play an important role in Notch-Hes-GATA signaling regulation, which disorders hematopoietic cells differentiation.

\section{Transcriptional factors related to hematopoiesis The GATA family}

GATA binding proteins, known to be the erythroid-specific transcription factor family, have a revolutionary significance in understanding the development of precursors from hematopoietic 
stem and progenitor cells, the generation of red blood cells from progenitors and the regulation of hemoglobin synthesis[51]. All members of the GATA family have highly conserved DNA-binding proteins that recognize the motif WGATAR through two zinc fingers to regulate the transcription of downstream target genes[52-54]. Millions of copies of the specific sequences of DNA in genome present in upstream of gene transcriptional origin, like promoters, enhancers and locus control regions of $\beta$-globin and other genes, including itself as an autoregulatory mechanism[51, 55]. The $\mathrm{C}$ terminal zinc finger specifically binds to the GATA consensus sites, whereas the $\mathrm{N}$ terminal zinc finger stabilizes the interaction between GATA and specific DNA sequences as well as regulates the transcriptional activity of GATA factors through recruiting other cofactors of zinc finger protein, such as FOG1, CPB/p300, Pax5 and Pu.1[56-60].

Among the six members (GATA1-6) of GATA family, GATA1 is the founding member and ushered in the cloning of the related proteins GATA2-6, and both GATA1, 2 and GATA3 are expressed in specific hematopoietic cell types of all stages. Involved in distinct and overlapping aspects of hematopoiesis, the three members play an essential role in the development and maintenance of diverse blood cell lineages, and are indispensable for regulating the development and maturation of red blood cell[51, 61]. GATA1 is a prototypical transcriptional factor required for the erythroid, eosinophilic and megakaryocytic commitment during hematopoiesis, taking part in the terminal differentiation. GATA2, predominantly expressed in hematopoietic stem and progenitor cells, is essential for maintenance of the pool of hematopoietic stem cells by regulating the proliferation and survival of early hematopoietic cells, and is also one of the most critical transcriptional factors required for direct induction of the hemogenic endothelium with pan-myeloid potential from human pluripotent stem cells[62, 63]. Both GATA1 and GATA2 are involved in lineage specific transcriptional regulation, especially the dynamic and strictly controlled GATA factor switching from GATA2 to GATA1 during erythropoiesis plays a crucial role in orchestrating erythroid lineage differentiation[64, 65], whereas GATA3 is of vital importance for multiorgan development and regulates tissue specific differentiation, it plays an essential role in $\mathrm{T}$ lymphoid cell development and immune regulation as well[54, 66, 67]. Therefore, alteration of GATA factors expression is closely associated with hematologic disorders and related diseases[55, 68]. No or less GATA1 expression notably influences the differentiation and maturation of erythroid cells, massive apoptosis of proerythroblasts leads to anemia[55]. Besides, GATA1-deficient mice develop thrombocytopenia and hyperproliferation of megakaryocytes due to dysmaturity of megakaryocytes and a failure of platelet production[69]. GATA2 mutation is associated with immunodeficiency, lymphedema, and myelodysplastic syndrome[70-72]. Inherited GATA3 variants are related to Ph-like childhood acute lymphoblastic leukemia and risk of relapse[73].

Researches have revealed some correlations between GATA family and the Notch signaling pathway, which is also involved in hematopoietic system[74-78]. It was found that Notch signals could inhibit the differentiation and maturation of erythroid/megakaryocytic cells by suppressing 
GATA-1 activity through the induction of Hes1expression[74].

\section{The Notch-Hes pathway}

Notch proteins are a family of evolutionarily highly conserved single-pass transmembrane receptors which are involved in the regulation of cell fate acquisition and differentiation in diverse systems. The notch signaling pathways not only play an essential part in the development of a wide range of tissues such as hemopoiesis, vasculogenesis, myogenesis, neurogenesis and osteogenesis, but also take part in the homeostasis maintenance of a broad variety tissues [79, 80]. The family comprises of four Notch receptors(Notch1-4), five structurally related, single-pass membrane Notch ligands (Delta-like1, 3, and 4 and Jagged1 and 2), and specific factors including the DNA-binding protein RBP-JK (recombinant binding protein suppressor of hairless; also known as $\mathrm{CSL} / \mathrm{CBF} 1$ in mammals, $\mathrm{Su}(\mathrm{H})$ in flies, and Lag-1 in worms) and the Mastermind-like family (MAML) [81, 82].

In the absence of Notch activation, the Notch intracellular domain (NICD) is unavailable and the downstream effector protein RBP-JK associates with several different corepressors containing Mint/Sharp/SPEN, NCoR/SMRT and KyoT2 to form a transcriptional corepressor complex which is bound to the chromatin and inhibits gene expression. Activation of the canonical Notch signaling is achieved by the generation of NICD, which is mediated by the interaction between receptors and ligands and subsequently a sequence of proteolytic events, as well as its eventual translocation to the nucleus where the RBP-JK association module (RAM) domain of NICD initially binds the RBP-Jк. This leads to the displacement of the co-repressor complex and the recruitment of the transcriptional co-activators like MAML to form a transcriptional activator complex (NICD-RBP-Jк-MAML), which triggers the downstream expression gene expression by recruiting transcriptional factors like p300 histone acetyl-transferase[79-84]. The various target genes of Notch including Hes(hairy/enhancer-of-split) and the Hes-related (HESR/HEY) family of basic helix-loop-helix transcription repressors, which are essential regulators of hematopoietic stem cell development, and subsequently modulate the proliferation and differentiation via regulating expression of other genes like GATA family[85, 86]. In addition, GATA2 was also identified as a direct target of Notch1 signaling, which revealed a crucial role of Notch activation for the onset of definitive hematopoiesis in the embryo[87].

Studies have identified Notch signaling as a key regulator of hematopoietic stem cell development[83, 84, 88-92]. Among the Notch and Hes family members, Notch1,2 and Hes1,5 are widely expressed in all lineages of hemopoietic stem/progenitor cells, and participate in regulating their proliferation and differentiation to generate various hemocytes complying with extremely strict principle of spatial-temporal sequence mediated by the fine expression of GATA factors[74, 83-87]. Activation of Notch1 signaling could inhibit the differentiation and maturation of EPCs and exhibit a peripherical hemogram of increased immature red blood cells and distinctly decreased counts of mature red blood cells[86, 93, 94], which might be a clue of building a bridge between B19 infection and anemia. 


\section{The pathway of B19 NS1 in regulation of EPCs differentiation}

Even though up to now no research has clarified if the major pathogenic factor B19 NS1 could influence the process of proliferation and differentiation via manipulating Notch signaling in B19-infected EPCs, evidences of the connection to Notch have been found in other virus infected cells[95]. Epstein-Barr virus nuclear antigen 2 (EBNA2) exerts its transactivating function through interaction with CBF1/RBP-J $\kappa$, which is the coactivator of Notch signaling[96]. Notch signaling is involved in the establishment of EBV latency in B cells possibly due to competitive binding of EBNA2 to CBF1/RBP-JK and the suppression of Notch/RBP-J signaling pathway which promotes B cell proliferative responses[95, 97]. In addition, RTA, the lytic cycle regulator of Kaposi's sarcoma-associated herpesvirus (KSHV), also interacts with RBP-Jא to activate gene expression [98]. Furthermore, Notch pathway interactions have also been mentioned for adenovirus SV40 and human papilloma virus[99, 100].

It has been identified that B19 could inhibit the differentiation of erythroid lineage cells both in vivo and vitro mediated by its major pathogenic factor NS1[1, 17]. The Notch signaling pathway also plays an essential part in hemopoiesis through regulating its downstream genes like Hes1/5 and GATA factors[83, 85]. Our tentative exploration showed that expression of Notch1, Hes1/5 and GATA2 upregulated while GATA1 downregulated in the B19 NS1 transfected K562 cells, which implies that NS1 could perturb the differentiation of erythroid lineage cells via manipulating Notch signaling, leading to alteration of expressional patterns of target gene Hes and GATA factors (unpublished data). The crosslink provides a new insight of the potential mechanism of B19-induced differentiational inhibition of EPCs. Further studies are needed to explore the expressional alteration of related target genes and the concrete regulatory pathway of Notch signaling to have a clearer understanding of the pathogenesis of B19-related anemia (Figure 3).

\section{Conclusion}

In summary, in this review, we provide a new insight of the bridge between B19 infection and Notch signaling pathway or transcriptional factors GATA: B19 NS1 could perturb the differentiation and proliferation processes of erythroid lineage cells via manipulating Notch signaling, leading to alteration of expressional patterns of target gene Hes and GATA factors. The crosslink provides a new potential mechanism of B19-induced differentiational inhibition of erythroid progenitor cells, may also give a clue to prophylactic and therapeutic targets for B19-related severe anemia in high risk groups, and develop effective vaccines or antivirus drugs of B19 infection.

\section{Ethics approval and consent to participate}

Not applicable.

\section{Consent for publication}

Not applicable. 
347

348

349

350

351

352

353

354

355

356

357

358

359

360

361

362

363

364

\section{Availability of data and material}

Not applicable.

\section{Competing interests}

No potential competing interests.

\section{Funding}

This work was supported by a grant from the Chinese National Natural Science Fund 81170005 and 81670007.

\section{Authors contributions:}

Dr. Shuwen Feng collecting references, drawing the figures and writing this paper, and Dr. Dongxin Zeng and Junwen Zheng participated the writing and discussion, and Dr. Dongchi Zhao writing and organizing this paper.

\section{Acknowledgements}

Thanks for professor the economic support by Natural Science Foundation of China. 
365

366

367

368

369

370

371

372

373

374

375

376

377

378

379

380

381

382

383

384

385

386

387

388

389

390

391

392

393

394

395

396

397

398

399

400

401

402

403

404

405

406

407

408

\section{References}

1. Qiu J, Soderlund-Venermo M, Young NS. Human Parvoviruses. Clin Microbiol Rev. 2017;30(1):43-113.

2. Lehmann HW, von Landenberg P, Modrow S. Parvovirus B19 infection and autoimmune disease. Autoimmun Rev. 2003;2(4):218-23.

3. Heegaard ED, Brown KE. Human parvovirus B19. Clin Microbiol Rev. 2002;15(3):485-505.

4. Nicolay N, Cotter S. Clinical and epidemiological aspects of parvovirus B19 infections in Ireland, January 1996-June 2008. Euro Surveill. 2009;14(25).

5. Marano G, Vaglio S, Pupella S, Facco G, Calizzani G, Candura F, et al. Human Parvovirus B19 and blood product safety: a tale of twenty years of improvements. Blood Transfus. 2015;13(2):184-96. 6. Mossong J, Hens N, Friederichs V, Davidkin I, Broman M, Litwinska B, et al. Parvovirus B19 infection in five European countries: seroepidemiology, force of infection and maternal risk of infection. Epidemiol Infect. 2008;136(8):1059-68.

7. Manaresi E, Gallinella G, Venturoli S, Zerbini M, Musiani M. Detection of parvovirus B19 IgG: choice of antigens and serological tests. J Clin Virol. 2004;29(1):51-3.

8. Servey JT, Reamy BV, Hodge J. Clinical presentations of parvovirus B19 infection. Am Fam Physician. 2007;75(3):373-6.

9. Kurtzman GJ, Ozawa K, Cohen B, Hanson G, Oseas R, Young NS. Chronic bone marrow failure due to persistent B19 parvovirus infection. N Engl J Med. 1987;317(5):287-94.

10. Oakley J, Zahr R, Aban I, Kulkarni V, Patel RP, Hurwitz J, et al. Acute Kidney Injury during Parvovirus B19-Induced Transient Aplastic Crisis in Sickle Cell Disease. Am J Hematol. 2018.

11. Dijkmans AC, de Jong EP, Dijkmans BA, Lopriore E, Vossen A, Walther FJ, et al. Parvovirus B19 in pregnancy: prenatal diagnosis and management of fetal complications. Curr Opin Obstet Gynecol. 2012;24(2):95-101.

12. Staroselsky A, Klieger-Grossmann C, Garcia-Bournissen F, Koren G. Exposure to fifth disease in pregnancy. Can Fam Physician. 2009;55(12):1195-8.

13. Bonvicini F, Bua G, Gallinella G. Parvovirus B19 infection in pregnancy-awareness and opportunities. Curr Opin Virol. 2017;27:8-14.

14. Kyeong KS, Won HS, Lee MY, Shim JY, Lee PR, Kim A. Clinical features of 10 fetuses with prenatally diagnosed parvovirus b19 infection and fetal hydrops. Fetal Pediatr Pathol. 2015;34(1):49-56.

15. Mace G, Sauvan M, Castaigne V, Moutard ML, Cortey A, Maisonneuve E, et al. Clinical presentation and outcome of 20 fetuses with parvovirus B19 infection complicated by severe anemia and/or fetal hydrops. Prenat Diagn. 2014;34(11):1023-30.

16. de Jong EP, de Haan TR, Kroes AC, Beersma MF, Oepkes D, Walther FJ. Parvovirus B19 infection in pregnancy. J Clin Virol. 2006;36(1):1-7.

17. Xu P, Zhou Z, Xiong M, Zou W, Deng X, Ganaie SS, et al. Parvovirus B19 NS1 protein induces cell cycle arrest at G2-phase by activating the ATR-CDC25C-CDK1 pathway. PLoS Pathog. 2017;13(3):e1006266.

18. dos Santos Brito Silva Furtado M, Viana MB, Hickson Rrios JS, Gontijo RL, Silva CM, do Val Rezende P, et al. Prevalence and incidence of erythrovirus B19 infection in children with sickle cell disease: The impact of viral infection in acute clinical events. J Med Virol. 2016;88(4):588-95.

19. Means RT, Jr. Pure red cell aplasia. Blood. 2016;128(21):2504-9. 
20. Chisaka H, Morita E, Yaegashi N, Sugamura K. Parvovirus B19 and the pathogenesis of anaemia. Rev Med Virol. 2003;13(6):347-59. Epub 2003/11/20.

21. Brown KE, Anderson SM, Young NS. Erythrocyte P antigen: cellular receptor for B19 parvovirus. Science. 1993;262(5130):114-7.

22. Weigel-Kelley KA, Yoder MC, Srivastava A. Recombinant human parvovirus B19 vectors: erythrocyte $\mathrm{P}$ antigen is necessary but not sufficient for successful transduction of human hematopoietic cells. J Virol. 2001;75(9):4110-6.

23. Brown KE, Hibbs JR, Gallinella G, Anderson SM, Lehman ED, McCarthy P, et al. Resistance to parvovirus B19 infection due to lack of virus receptor (erythrocyte P antigen). N Engl J Med. 1994;330(17):1192-6. Epub 1994/04/28.

24. Weigel-Kelley KA, Yoder MC, Srivastava A. Alpha5beta1 integrin as a cellular coreceptor for human parvovirus B19: requirement of functional activation of beta1 integrin for viral entry. Blood. 2003;102(12):3927-33.

25. Munakata Y, Saito-Ito T, Kumura-Ishii K, Huang J, Kodera T, Ishii T, et al. Ku80 autoantigen as a cellular coreceptor for human parvovirus B19 infection. Blood. 2005;106(10):3449-56.

26. Kaufmann B, Simpson AA, Rossmann MG. The structure of human parvovirus B19. Proc Natl Acad Sci U S A. 2004;101(32):11628-33.

27. Zhi N, Mills IP, Lu J, Wong S, Filippone C, Brown KE. Molecular and functional analyses of a human parvovirus B19 infectious clone demonstrates essential roles for NS1, VP1, and the 11-kilodalton protein in virus replication and infectivity. J Virol. 2006;80(12):5941-50.

28. Peterlana D, Puccetti A, Corrocher R, Lunardi C. Serologic and molecular detection of human Parvovirus B19 infection. Clin Chim Acta. 2006;372(1-2):14-23.

29. Luo W, Astell CR. A novel protein encoded by small RNAs of parvovirus B19. Virology. 1993;195(2):448-55.

30. St Amand J, Beard C, Humphries K, Astell CR. Analysis of splice junctions and in vitro and in vivo translation potential of the small, abundant B19 parvovirus RNAs. Virology. 1991;183(1):133-42. 31. Chen AY, Zhang EY, Guan W, Cheng F, Kleiboeker S, Yankee TM, et al. The small $11 \mathrm{kDa}$ nonstructural protein of human parvovirus B19 plays a key role in inducing apoptosis during B19 virus infection of primary erythroid progenitor cells. Blood. 2010;115(5):1070-80.

32. Ganaie SS, Chen AY, Huang C, Xu P, Kleiboeker S, Du A, et al. RNA Binding Protein RBM38 Regulates Expression of the 11-Kilodalton Protein of Parvovirus B19, Which Facilitates Viral DNA Replication. J Virol. 2018;92(8).

33. Ozawa K, Ayub J, Kajigaya S, Shimada T, Young N. The gene encoding the nonstructural protein of B19 (human) parvovirus may be lethal in transfected cells. J Virol. 1988;62(8):2884-9.

34. Ganaie SS, Qiu J. Recent Advances in Replication and Infection of Human Parvovirus B19. Front Cell Infect Microbiol. 2018;8:166.

35. Raab U, Beckenlehner K, Lowin T, Niller HH, Doyle S, Modrow S. NS1 protein of parvovirus B19 interacts directly with DNA sequences of the p6 promoter and with the cellular transcription factors Sp1/Sp3. Virology. 2002;293(1):86-93.

36. Tewary SK, Zhao H, Deng X, Qiu J, Tang L. The human parvovirus B19 non-structural protein 1 $\mathrm{N}$-terminal domain specifically binds to the origin of replication in the viral DNA. Virology. 2014;449:297-303.

37. Sanchez JL, Romero Z, Quinones A, Torgeson KR, Horton NC. DNA Binding and Cleavage by the Human Parvovirus B19 NS1 Nuclease Domain. Biochemistry. 2016;55(47):6577-93. 
38. Fu Y, Ishii KK, Munakata Y, Saitoh T, Kaku M, Sasaki T. Regulation of tumor necrosis factor alpha promoter by human parvovirus B19 NS1 through activation of AP-1 and AP-2. J Virol. 2002;76(11):5395-403.

39. Moffatt S, Tanaka N, Tada K, Nose M, Nakamura M, Muraoka O, et al. A cytotoxic nonstructural protein, NS1, of human parvovirus B19 induces activation of interleukin-6 gene expression. J Virol. 1996;70(12):8485-91. Epub 1996/12/01.

40. Nakashima A, Morita E, Saito S, Sugamura K. Human Parvovirus B19 nonstructural protein transactivates the p21/WAF1 through Sp1. Virology. 2004;329(2):493-504.

41. Moffatt S, Yaegashi N, Tada K, Tanaka N, Sugamura K. Human parvovirus B19 nonstructural (NS1) protein induces apoptosis in erythroid lineage cells. J Virol. 1998;72(4):3018-28.

42. Hsu TC, Wu WJ, Chen MC, Tsay GJ. Human parvovirus B19 non-structural protein (NS1) induces apoptosis through mitochondria cell death pathway in COS-7 cells. Scand J Infect Dis. 2004;36(8):570-7.

43. Luo Y, Lou S, Deng X, Liu Z, Li Y, Kleiboeker S, et al. Parvovirus B19 infection of human primary erythroid progenitor cells triggers ATR-Chk1 signaling, which promotes B19 virus replication. J Virol. 2011;85(16):8046-55.

44. Morita E, Tada K, Chisaka H, Asao H, Sato H, Yaegashi N, et al. Human parvovirus B19 induces cell cycle arrest at G(2) phase with accumulation of mitotic cyclins. J Virol. 2001;75(16):7555-63.

45. Kivovich V, Gilbert L, Vuento M, Naides SJ. The putative metal coordination motif in the endonuclease domain of human Parvovirus B19 NS1 is critical for NS1 induced S phase arrest and DNA damage. International journal of biological sciences. 2012;8(1):79-92. Epub 2012/01/03.

46. Luo Y, Kleiboeker S, Deng X, Qiu J. Human parvovirus B19 infection causes cell cycle arrest of human erythroid progenitors at late $\mathrm{S}$ phase that favors viral DNA replication. J Virol. 2013;87(23):12766-75. Epub 2013/09/21.

47. Wan Z, Zhi N, Wong S, Keyvanfar K, Liu D, Raghavachari N, et al. Human parvovirus B19 causes cell cycle arrest of human erythroid progenitors via deregulation of the E2F family of transcription factors. J Clin Invest. 2010;120(10):3530-44.

48. Morita E, Nakashima A, Asao H, Sato H, Sugamura K. Human parvovirus B19 nonstructural protein (NS1) induces cell cycle arrest at G(1) phase. J Virol. 2003;77(5):2915-21. Epub 2003/02/14.

49. Poole BD, Kivovich V, Gilbert L, Naides SJ. Parvovirus B19 nonstructural protein-induced damage of cellular DNA and resultant apoptosis. Int J Med Sci. 2011;8(2):88-96.

50. Zou W, Wang Z, Xiong M, Chen AY, Xu P, Ganaie SS, et al. Human Parvovirus B19 Utilizes Cellular DNA Replication Machinery for Viral DNA Replication. J Virol. 2018;92(5).

51. Katsumura KR, Bresnick EH, Group GFM. The GATA factor revolution in hematology. Blood. 2017;129(15):2092-102.

52. Ko LJ, Engel JD. DNA-binding specificities of the GATA transcription factor family. Mol Cell Biol. 1993;13(7):4011-22.

53. Trainor CD, Omichinski JG, Vandergon TL, Gronenborn AM, Clore GM, Felsenfeld G. A palindromic regulatory site within vertebrate GATA-1 promoters requires both zinc fingers of the GATA-1 DNA-binding domain for high-affinity interaction. Mol Cell Biol. 1996;16(5):2238-47.

54. Gao J, Chen YH, Peterson LC. GATA family transcriptional factors: emerging suspects in hematologic disorders. Exp Hematol Oncol. 2015;4:28.

55. Crispino JD, Horwitz MS. GATA factor mutations in hematologic disease. Blood. 2017;129(15):2103-10. 
56. Tsang AP, Visvader JE, Turner CA, Fujiwara Y, Yu C, Weiss MJ, et al. FOG, a multitype zinc finger protein, acts as a cofactor for transcription factor GATA-1 in erythroid and megakaryocytic differentiation. Cell. 1997;90(1):109-19.

57. Takahashi T, Suwabe N, Dai P, Yamamoto M, Ishii S, Nakano T. Inhibitory interaction of c-Myb and GATA-1 via transcriptional co-activator CBP. Oncogene. 2000;19(1):134-40.

58. Heavey B, Charalambous C, Cobaleda C, Busslinger M. Myeloid lineage switch of Pax 5 mutant but not wild-type B cell progenitors by C/EBPalpha and GATA factors. EMBO J. 2003;22(15):3887-97. 59. Nerlov C, Querfurth E, Kulessa H, Graf T. GATA-1 interacts with the myeloid PU.1 transcription factor and represses PU.1-dependent transcription. Blood. 2000;95(8):2543-51.

60. Cantor AB, Orkin SH. Transcriptional regulation of erythropoiesis: an affair involving multiple partners. Oncogene. 2002;21(21):3368-76.

61. Chlon TM, Crispino JD. Combinatorial regulation of tissue specification by GATA and FOG factors. Development. 2012;139(21):3905-16.

62. Elcheva I, Brok-Volchanskaya V, Kumar A, Liu P, Lee JH, Tong L, et al. Direct induction of haematoendothelial programs in human pluripotent stem cells by transcriptional regulators. Nat Commun. 2014;5:4372.

63. Rodrigues NP, Boyd AS, Fugazza C, May GE, Guo Y, Tipping AJ, et al. GATA-2 regulates granulocyte-macrophage progenitor cell function. Blood. 2008;112(13):4862-73.

64. Suzuki M, Kobayashi-Osaki M, Tsutsumi S, Pan X, Ohmori S, Takai J, et al. GATA factor switching from GATA2 to GATA1 contributes to erythroid differentiation. Genes Cells. 2013;18(11):921-33.

65. Moriguchi T, Yamamoto M. A regulatory network governing Gata1 and Gata2 gene transcription orchestrates erythroid lineage differentiation. Int J Hematol. 2014;100(5):417-24.

66. Garcia-Ojeda ME, Klein Wolterink RG, Lemaitre F, Richard-Le Goff O, Hasan M, Hendriks RW, et al. GATA-3 promotes T-cell specification by repressing B-cell potential in pro-T cells in mice. Blood. 2013;121(10):1749-59.

67. Scripture-Adams DD, Damle SS, Li L, Elihu KJ, Qin S, Arias AM, et al. GATA-3 dose-dependent checkpoints in early T cell commitment. J Immunol. 2014;193(7):3470-91.

68. Shimizu R, Yamamoto M. GATA-related hematologic disorders. Exp Hematol. 2016;44(8):696-705.

69. Vyas P, Ault K, Jackson CW, Orkin SH, Shivdasani RA. Consequences of GATA-1 deficiency in megakaryocytes and platelets. Blood. 1999;93(9):2867-75.

70. Schlums H, Jung M, Han H, Theorell J, Bigley V, Chiang SC, et al. Adaptive NK cells can persist in patients with GATA2 mutation depleted of stem and progenitor cells. Blood. 2017;129(14):1927-39.

71. Spinner MA, Sanchez LA, Hsu AP, Shaw PA, Zerbe CS, Calvo KR, et al. GATA2 deficiency: a protean disorder of hematopoiesis, lymphatics, and immunity. Blood. 2014;123(6):809-21.

72. Hsu AP, McReynolds LJ, Holland SM. GATA2 deficiency. Curr Opin Allergy Clin Immunol. 2015;15(1):104-9.

73. Perez-Andreu V, Roberts KG, Harvey RC, Yang W, Cheng C, Pei D, et al. Inherited GATA3 variants are associated with Ph-like childhood acute lymphoblastic leukemia and risk of relapse. Nat Genet. 2013;45(12):1494-8.

74. Ishiko E, Matsumura I, Ezoe S, Gale K, Ishiko J, Satoh Y, et al. Notch signals inhibit the development of erythroid/megakaryocytic cells by suppressing GATA-1 activity through the induction of HES1. J Biol Chem. 2005;280(6):4929-39. 
75. de Pooter RF, Schmitt TM, de la Pompa JL, Fujiwara Y, Orkin SH, Zuniga-Pflucker JC. Notch signaling requires GATA-2 to inhibit myelopoiesis from embryonic stem cells and primary hemopoietic progenitors. J Immunol. 2006;176(9):5267-75. Epub 2006/04/20.

76. Ross J, Mavoungou L, Bresnick EH, Milot E. GATA-1 utilizes Ikaros and polycomb repressive complex 2 to suppress Hes1 and to promote erythropoiesis. Mol Cell Biol. 2012;32(18):3624-38. 77. Malinge S, Thiollier C, Chlon TM, Dore LC, Diebold L, Bluteau O, et al. Ikaros inhibits megakaryopoiesis through functional interaction with GATA-1 and NOTCH signaling. Blood. 2013;121(13):2440-51.

78. Terriente-Felix A, Li J, Collins S, Mulligan A, Reekie I, Bernard F, et al. Notch cooperates with Lozenge/Runx to lock haemocytes into a differentiation programme. Development. 2013;140(4):926-37.

79. Siebel C, Lendahl U. Notch Signaling in Development, Tissue Homeostasis, and Disease. Physiol Rev. 2017;97(4):1235-94.

80. Andersson ER, Sandberg R, Lendahl U. Notch signaling: simplicity in design, versatility in function. Development. 2011;138(17):3593-612.

81. Kopan R, Ilagan MX. The canonical Notch signaling pathway: unfolding the activation mechanism. Cell. 2009;137(2):216-33. Epub 2009/04/22.

82. Wang H, Zang C, Liu XS, Aster JC. The role of Notch receptors in transcriptional regulation. J Cell Physiol. 2015;230(5):982-8.

83. Bigas A, Guiu J, Gama-Norton L. Notch and Wnt signaling in the emergence of hematopoietic stem cells. Blood Cells Mol Dis. 2013;51(4):264-70.

84. Lampreia FP, Carmelo JG, Anjos-Afonso F. Notch Signaling in the Regulation of Hematopoietic Stem Cell. Curr Stem Cell Rep. 2017;3(3):202-9.

85. Guiu J, Shimizu R, D'Altri T, Fraser ST, Hatakeyama J, Bresnick EH, et al. Hes repressors are essential regulators of hematopoietic stem cell development downstream of Notch signaling. J Exp Med. 2013;210(1):71-84.

86. Kumano K, Chiba S, Shimizu K, Yamagata T, Hosoya N, Saito T, et al. Notch1 inhibits differentiation of hematopoietic cells by sustaining GATA-2 expression. Blood. 2001;98(12):3283-9.

87. Robert-Moreno A, Espinosa L, de la Pompa JL, Bigas A. RBPjkappa-dependent Notch function regulates Gata 2 and is essential for the formation of intra-embryonic hematopoietic cells. Development. 2005;132(5):1117-26.

88. $\mathrm{Gu} \mathrm{Y}$, Masiero M, Banham AH. Notch signaling: its roles and therapeutic potential in hematological malignancies. Oncotarget. 2016;7(20):29804-23.

89. Robert-Moreno A, Guiu J, Ruiz-Herguido C, Lopez ME, Ingles-Esteve J, Riera L, et al. Impaired embryonic haematopoiesis yet normal arterial development in the absence of the Notch ligand Jagged1. Embo j. 2008;27(13):1886-95. Epub 2008/06/06.

90. Zeuner A, Francescangeli F, Signore M, Venneri MA, Pedini F, Felli N, et al. The Notch2-Jagged1 interaction mediates stem cell factor signaling in erythropoiesis. Cell Death Differ. 2011;18(2):371-80. Epub 2010/09/11.

91. Kim AD, Melick CH, Clements WK, Stachura DL, Distel M, Panakova D, et al. Discrete Notch signaling requirements in the specification of hematopoietic stem cells. EMBO J. 2014;33(20):2363-73.

92. Duarte S, Woll PS, Buza-Vidas N, Chin DWL, Boukarabila H, Luis TC, et al. Canonical Notch signaling is dispensable for adult steady-state and stress myelo-erythropoiesis. Blood. 
585

586

587

588

589

590

591

592

593

594

595

596

597

598

599

600

601

602

603

604

605

606

607

608

609

610

611

612

613

614

615

616

617

618

619

620

621

622

623

624

625

2018;131(15):1712-9.

93. Cheng X, Huber TL, Chen VC, Gadue P, Keller GM. Numb mediates the interaction between Wnt and Notch to modulate primitive erythropoietic specification from the hemangioblast. Development. 2008;135(20):3447-58. Epub 2008/09/19.

94. Kim YW, Koo BK, Jeong HW, Yoon MJ, Song R, Shin J, et al. Defective Notch activation in microenvironment leads to myeloproliferative disease. Blood. 2008;112(12):4628-38.

95. Hayward SD. Viral interactions with the Notch pathway. Semin Cancer Biol. 2004;14(5):387-96.

96. Zimber-Strobl U, Strobl LJ, Meitinger C, Hinrichs R, Sakai T, Furukawa T, et al. Epstein-Barr virus nuclear antigen 2 exerts its transactivating function through interaction with recombination signal binding protein RBP-J kappa, the homologue of Drosophila Suppressor of Hairless. EMBO J. 1994;13(20):4973-82.

97. Kuroda K, Han H, Tani S, Tanigaki K, Tun T, Furukawa T, et al. Regulation of marginal zone B cell development by MINT, a suppressor of Notch/RBP-J signaling pathway. Immunity. 2003;18(2):301-12.

98. Liang Y, Chang J, Lynch SJ, Lukac DM, Ganem D. The lytic switch protein of KSHV activates gene expression via functional interaction with RBP-Jkappa (CSL), the target of the Notch signaling pathway. Genes Dev. 2002;16(15):1977-89.

99. Bocchetta M, Miele L, Pass HI, Carbone M. Notch-1 induction, a novel activity of SV40 required for growth of SV40-transformed human mesothelial cells. Oncogene. 2003;22(1):81-9.

100. Nair P, Somasundaram K, Krishna S. Activated Notch1 inhibits p53-induced apoptosis and sustains transformation by human papillomavirus type 16 E6 and E7 oncogenes through a PI3K-PKB/Akt-dependent pathway. J Virol. 2003;77(12):7106-12.

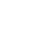


626

627

628

629

630

631

632

633

634

635

636

637

638

639

640

641

642

643

644

645

646

647

648

649

650

651

652

653

654

655

656

657

658

659

660

661

662

663

Figure legends

Figure 1. Mechanism of B19 causing erythropoiesis hemolysis. B19 entry erythropoiesis by binding $\alpha 5 \beta 1$ integrins and coaction with $\mathrm{p}$ antigen. Replication of B19 leads to cytolysis of EPCs and influences the life span of erythropoiesis cells, which brings about acute hemolysis.

Figure 2. Roles of nonstructural protein 1 in B19 infection. Replication of B19 virus promotes its NS1 covalently binding with host cellar DNA, induces CCA at G1-phase in NS1-expressing UT7/Epo-S1 cells and causing DDR mediated by helicase and nickase in NS1 central region, resultantly perturbs cell cycle progression and inhibit the differentiation of EPCs.

Figure 3.Putative pathways of nonstructural protein 1 in the regulation of EPCs differentiation. B19 NS1 upregulates the expression of Notch1, Hes1/5 and GATA2, while downregulates GATA1, which perturbs the differentiation of erythroid lineage cells via manipulating Notch signaling, leading to alteration of expressional patterns of Hes and GATA.

(1)

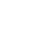

(1)

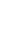

(1)

(1)

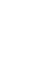


664 Figure 1.

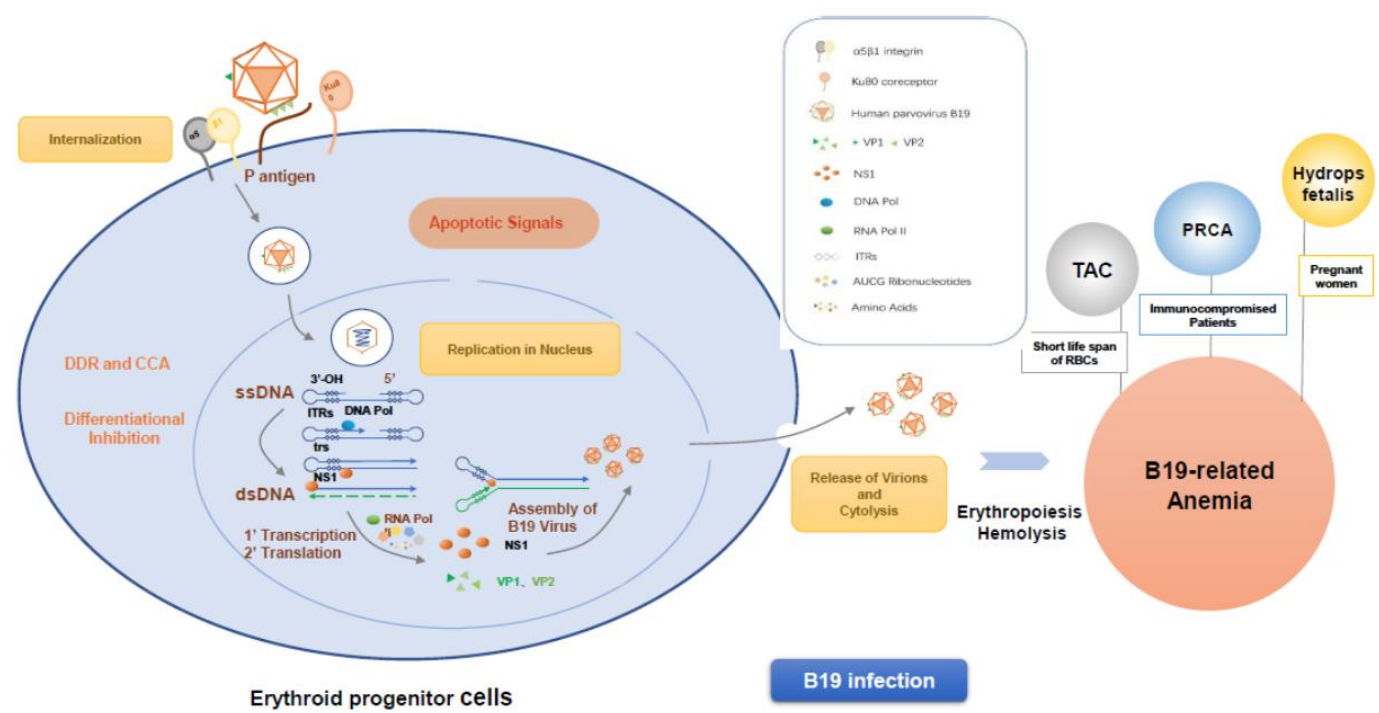

665

Figure 1

666

667

668

669

670

671

672

673

674

675

676

677

678

679

680

681

682

683

684

685

686

687

688

689 
690

Figure 2.

691

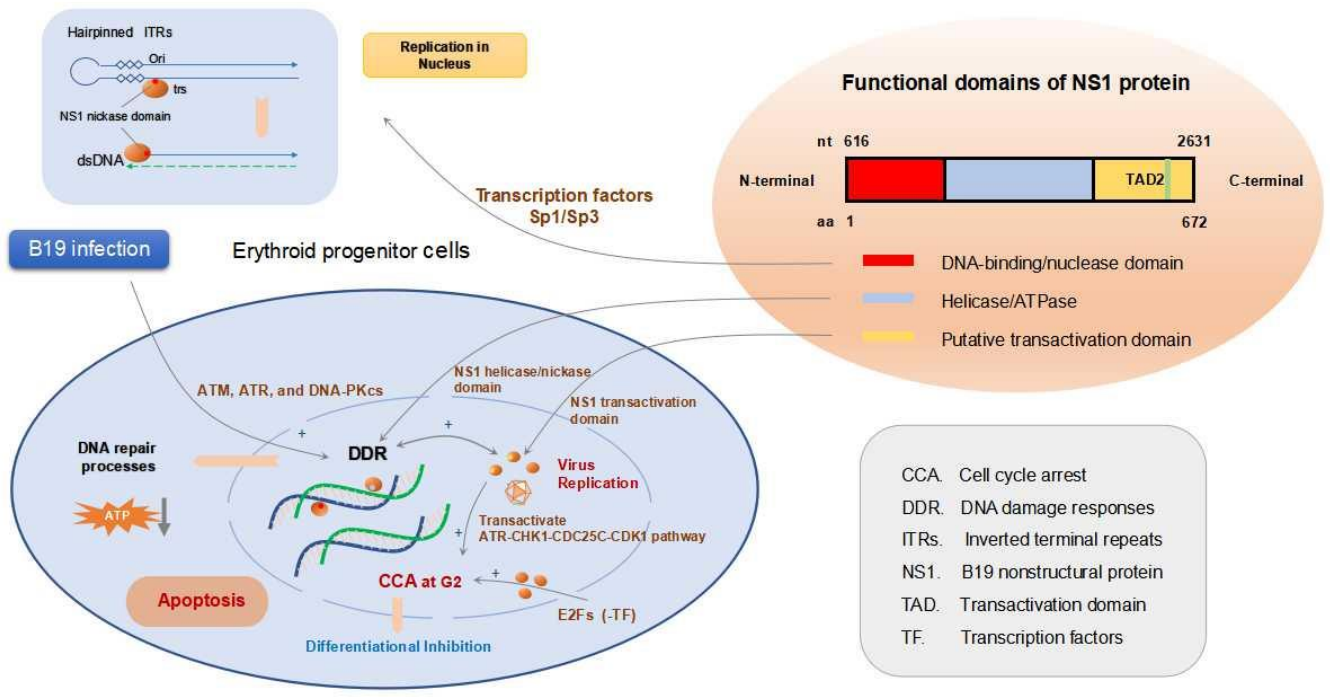

Figure2. Roles of nonstructural protein NS1 in B19 infection

692

693

694

695

696

697

698

699

700

701

702

703

704

705

706

707

708

709

710

711

712

713

714

715 
716

717

718

719
Figure 3

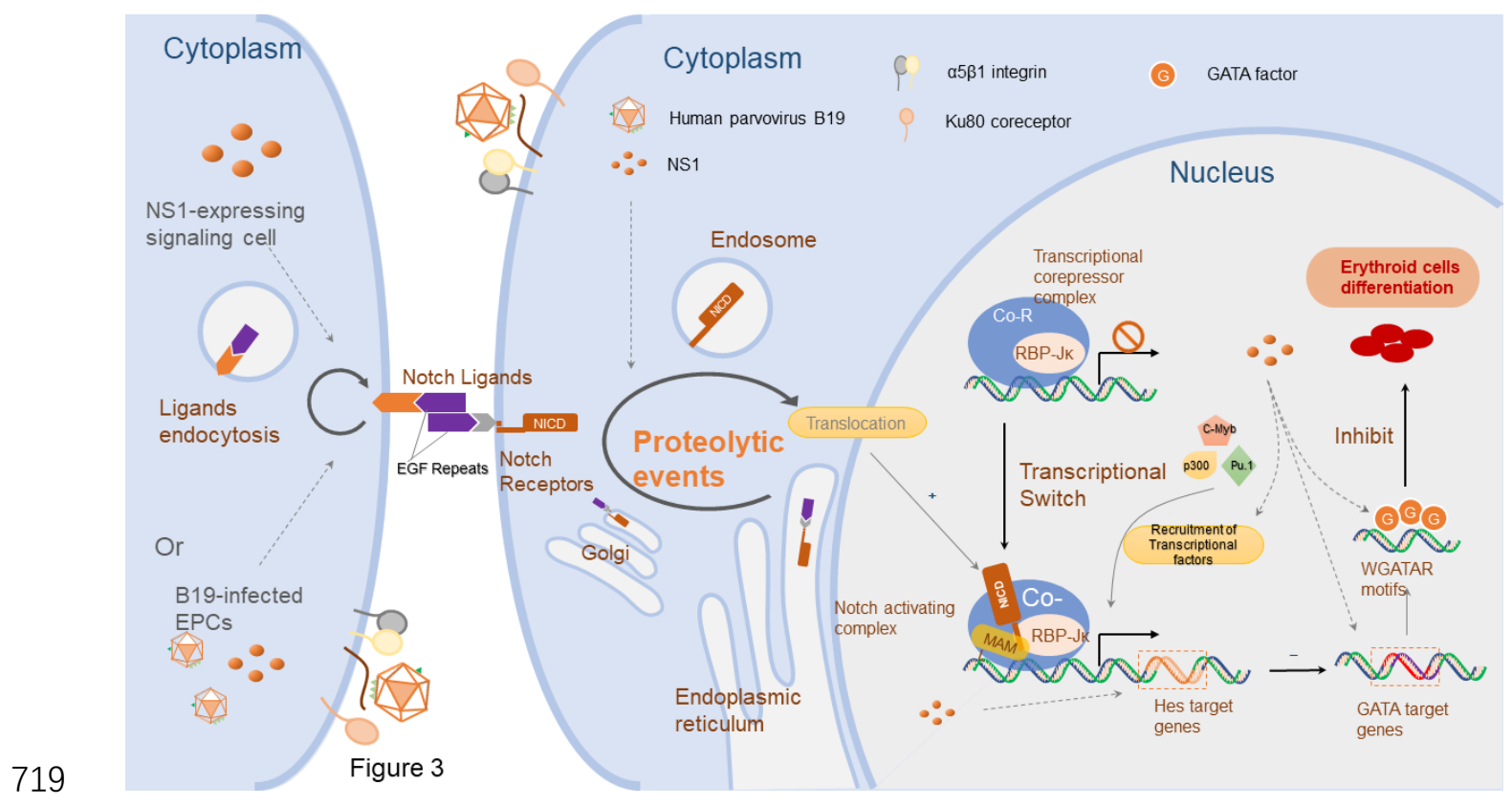

